\title{
Value of Serum Galectin-3 Levels as A Predictor of Thromboembolism in Nonvalvular AF
}

\author{
Saud M. Elsaughier*1, Mohamed Yassin Abdelradi', Mohamed Kamal Slama ${ }^{1}$, \\ Naggeh M. Mahmoud ${ }^{1}$, Amr Salah Amin ${ }^{2}$, Amr Hanafy ${ }^{1}$ \\ ${ }^{1}$ Cardiology Department, Faculty of Medicine, Aswan University, Aswan, Egypt. \\ ${ }^{2}$ Cardiology Department, Faculty of Medicine, Minia University, Minia, Egypt
}

*Corresponding author: Saud M. Elsaughier, Mobile: (+20)01157166779, E-mail: soud_elsoughier_66@yahoo.com.

\begin{abstract}
Background: Galactin is involved in process of cardiac fibrosis. It is not clear if there is an association between serum galactin level and thromboembolism events in atrial fibrillation (AF).

Objective: To investigate whether serum galactin levels can be used as a predictor for thromboembolism in patients with non-valvular AF or not.

Patients and Methods: We conducted a case-control study on 200 participants (100 individuals as a control, 50 patients with $\mathrm{AF}$ and thromboembolism and 50 patients with $\mathrm{AF}$ but without thromboembolism). We recruited patients from Cardiology Department, Aswan University Hospital who had non valvular AF. Participants were subjected to detailed medical history, clinical examination, electrocardiography, and ELISA test to evaluate serum galactin level. Results: Serum galactin was only predictor for thromboembolic event $(\mathrm{OR}=2.4,95 \% \mathrm{CI}=\{1.3: 4.3\}$, $\mathrm{P}$ value $=0.005)$ with a sensitivity of $73 \%$ and specificity of $65 \%$ for the thrombus detection $(\mathrm{AUC}=0.80,95 \% \mathrm{CI}=$ $\{0.69-0.89\}$ ). Serum galactin has a sensitivity of $81 \%$ and specificity of $77 \%$ to detect AF incidence (AUC $=0.84$, $95 \% \mathrm{CI}=\{0.73-0.99\})$. Serum galactin was correlated to CHADS-VASc score $(\mathrm{r}=0.75, \mathrm{p}$ value $<0.001)$ and LVEF $(\mathrm{r}=-0.586$, $\mathrm{p}$ value $<0.001)$.

Conclusion: Galactin-3 level is a possible predictor for thromboembolism in patients with non-valvular AF. Nevertheless, further studies are still needed to confirm our findings.
\end{abstract}

Keywords: Non-valvular AF, Thromboembolism, Galactin-3.

\section{INTRODUCTION}

Despite good progress in the management of patients with atrial fibrillation (AF), this arrhythmia remains one of the major causes of stroke, heart failure, sudden death, and cardiovascular morbidity in the world. Furthermore, the number of patients with $\mathrm{AF}$ is predicted to rise steeply in the coming years ${ }^{(\mathbf{1})}$. Traditionally, patients with AF have been dichotomized into valvular and non-valvular AF. Although slightly different definitions have been used, valvular AF generally refers to AF patients with moderate to severe mitral stenosis or prosthetic heart valves (and valve repair in North American guidelines) ${ }^{(2)}$.

In AF patients, reduced LAA flow velocity (LAAFV) and the presence of spontaneous echo contrast (SEC), an echogenic swirling pattern of blood flow, which indicates a low-flow state in the left atrium (LA). These have been shown to be markers of thromboembolic risk ${ }^{(3)}$. Studies have suggested a possible association between inflammation, $\mathrm{AF}$, and thrombosis. Levels of inflammatory makers, such as C-reactive protein (CRP) have been found to be related to LA/LAA-located SEC and thrombus observed on trans-esophageal echocardiography (TEE) ${ }^{(4,5)}$.

Galectin-3 is $\alpha$-galactoside-binding lectin that has been shown to mediate cell-to- cell and cell-toextracellular matrix interactions and act as a novel chemo-attractant for monocytes and macrophages ${ }^{(6)}$.
Studies have supported an association between serum galectin-3 levels and atrial fibrosis demonstrated with delayed-enhancement of magnetic resonance imaging in $\mathrm{AF}$ patients ${ }^{(7,8)}$. In this study, we investigated the possibility of using galactine-3 as a predictor of thromboembolism in non-valvular AF patients.

\section{PATIENTS AND METHODS}

Our study is a case-control study that was conducted from January 2018 to October 2019 at Cardiology Department, Aswan University Hospital and included 100 patients with non-valvular AF and 100 healthy control group. Then patients were divided into two subgroups: subgroup (A) 50 patients with nonvalvular AF with thromboembolic events and subgroup (B) 50 patients with non-valvular AF without thromboembolic events. Patients with Moderate to severe mitral stenosis and prosthetic valve, pregnant women, abnormal thyroid function, recent infection, Alcohol consumption, renal failure, and all patients with non-valvular $\mathrm{AF}$ on oral anticoagulant (warfarin and NOAC) were excluded from the study.

\section{Ethical approval:}

An approval of the study was obtained from Aswan University academic and ethical committee. All patients were informed about the purpose of the research, and written consent was obtained from each patient. 
All patients were subjected to:

1-History taking: A thorough history was taken from all members of the study group with special emphasis on age, sex, history of hypertension, history of diabetes mellitus, history of smoking, history of ischemic heart disease and calculation of CHA2DS2VASC score

2- Clinical evaluation: All patients were assessed clinically, including the evaluation of cardiovascular risk factors and general and local examination.

3- Electrocardiographic (ECG) evaluation: Twelve leads resting ECG was done for all patients to exclude any ischemic changes and to detect rate and rhythm.

4- Laboratory assessment: Blood sampling procedures and assay of serum galectin-3 level from peripheral vein samples of serum plasma were gotten. The blood samples were collected and immediately centrifuged at 2000-3000 rpm for 20 minutes and stored at $-80^{\circ} \mathrm{C}$. Plasma concentrations of Gal-3 were detected by an enzyme-linked immunosorbent assay kit (SinoGeneClon Biotech Co. Ltd). Procedure and calibration of assay was performed according to the manufacturer's protocol ${ }^{(\boldsymbol{9})}$. Briefly, plasma Gal-3 was bound to the anti-Gal-3 antibody, that was adsorbed onto micro-well plates and was captured with a secondary antibody anti-Gal-3 bio-tenanted (Sandwich method), that was revealed through the HRP-streptavidin exposed to TMB substrate. The colorimetric reaction was measured at $450 \mathrm{~nm}$ using an enzyme-linked immunosorbent assay (ELISA) plate reader. The standard curve ranged between $0.47 \mathrm{ng} / \mathrm{ml}$ to $30.00 \mathrm{ng} / \mathrm{ml}$. The limit of detection was $0.99 \mathrm{ng} / \mathrm{ml}$ and the reproducibility coefficient of variation of intra-assay and inter-assay were $3.3 \%$ and $6.8 \%$ respectively. In addition, routine biochemical work-up was performed including:

- Kidney function tests (urea, creatinine): Blood urea by colorimetric or automated chemical analyzer, serum creatinine by Jaffe reaction.

- Electrolytes (sodium, potassium, calcium): Sodium and potassium by atomic absorption spectrometer, ionized calcium by Ion Selective Electrodes.

- Measurement of thyroid function tests (TSH, free T3, and free T4): Enzyme Linked Fluorescent Assay (ELFA).

\section{5-Echocardiography:}

ECG trace transthoracic and transesophageal echocardiography examination were performed using Philips IE 33 machine with X5-1 MHz transducer. Images were obtained by a single operator blinded to clinical and biochemical information.

1) Transthoracic echocardiography was done in the left lateral position, while the patient holding breath after expiration and m-mode and $2 \mathrm{D}$ was acquired to evaluate regional wall motion abnormalities and left ventricular ejection fraction (10).

2) Transesophageal echocardiography parameters: All patients were fasted for at least $4 \mathrm{~h}$ and, then underwent TEE study. Sedation with 2-5mg I.V. Diazepam was used in all patients. The pharynx was anesthetized with topical $10 \%$ lidocaine spray, and the probe was introduced into the esophagus with the patient lying on the left side. The LAA was viewed from the basal short axis, with the tip of the probe slightly flexed to observe the whole length and breadth of the LAA. The procedure was performed with continuous monitoring of heart rate, blood pressure, and a 12lead electrocardiogram (11). Transesophageal echocardiography was tolerated well by all patients, and no complications occurred.

\section{Statistical analysis}

An independent $t$ test was conducted to compare continuous variables and the chi-square and Fisher's exact tests were performed to compare categorical variables. Continuous variables are expressed as mean and standard deviation, while categorical variables as frequency and percentage. A multivariate linear regression analysis was conducted to determine the independent correlation between average aortic valve sclerosis score index. $\mathrm{P}$ values equal or less than 0.05 was considered significant. We performed all statistical analyses using the Statistical Package for the Social Sciences/ Predictive Analytics Software version 18 (SPSS, Inc., Chicago, IL, USA).

\section{RESULT}

The mean age of the nonvalvular AF patients was $60.05 \pm 4.8$ years old and most of the patients were males. The patient's group was divided into two groups: Group (A) included 50 patients with $\mathrm{AF}$ and thromboembolic event. The mean age of these patients was $60.7 \pm 4.02$ years old and the majority of them were males $(60 \%)$. Group (B) included 50 patients with AF without thromboembolic event. The mean age of these patients was $59.4 \pm 5.44$ years old and the majority of them were males $(64 \%)$. There was no statistically significant difference between patient's groups and control group as regards age $(\mathrm{p}=0.148)$, gender $(\mathrm{p}=0.315$, BMI $(\mathrm{p}=0.367)$ and smoking $(\mathrm{p}=$ 0.188 ). Also, there was no statistically significant differences between the two patient's groups as regards age $(\mathrm{p}=0.177)$, gender $(\mathrm{p}=0.68)$, smoking $(\mathrm{p}$ $=0.102)$, and BMI $(\mathrm{p}=0.348)$ as shown in table $(1)$.

Table (1): Comparison between the two patient's groups regarding demographic data $(n=100)$ 


\begin{tabular}{|c|c|c|c|c|c|c|c|}
\hline & \multicolumn{3}{|c|}{ Groups } & \multirow{2}{*}{\multicolumn{3}{|c|}{ Test of sig. }} \\
\hline & & \multirow[b]{2}{*}{$\begin{array}{l}\text { Controls } \\
(\mathrm{N}=100)\end{array}$} & \multicolumn{2}{|c|}{ Non-Valvular AF $(\mathrm{N}=100)$} & & & \\
\hline & & & $\begin{array}{c}\text { AF without TE } \\
(N=50)\end{array}$ & $\begin{array}{c}\text { AF with TE } \\
(\mathbf{N}=50)\end{array}$ & \multirow{2}{*}{$\begin{array}{c}\text { P-Value } \\
\text { (1) }\end{array}$} & \multirow{2}{*}{$\begin{array}{l}\text { P-Value } \\
\text { (2) }\end{array}$} & \multirow{2}{*}{$\begin{array}{c}\text { P-Value } \\
\text { (3) }\end{array}$} \\
\hline & & $\begin{array}{c}\text { Mean } \pm \text { SD } \\
\text { N }(\%)\end{array}$ & $\begin{array}{c}\text { Mean } \pm \text { SD } \\
N(\%)\end{array}$ & $\begin{array}{c}\text { Mean } \pm \text { SD } \\
N(\%)\end{array}$ & & & \\
\hline \multicolumn{2}{|l|}{\begin{tabular}{|l|} 
Age \\
\end{tabular}} & $61.43 \pm 8.2$ & $59.4 \pm 5.44$ & $60.7 \pm 4.02$ & $0.073^{(\mathbf{T})}$ & $0.465^{(\mathrm{T})}$ & $0.177^{(\mathbf{T})}$ \\
\hline \multirow{2}{*}{ 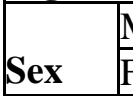 } & Male & $55(55 \%)$ & $32(64 \%)$ & $30(60 \%)$ & \multirow{2}{*}{$0.292^{(\mathbf{C})}$} & \multirow{2}{*}{$0.56^{(\mathrm{C})}$} & \multirow{2}{*}{$0.68^{(\mathrm{C})}$} \\
\hline & Gemale & $45(45 \%)$ & $18(36 \%)$ & $20(40 \%)$ & & & \\
\hline \multicolumn{2}{|l|}{ BMI } & $27.21 \pm 2.26$ & $27.74 \pm 3.04$ & $27.28 \pm 1.62$ & $0.231^{(\mathbf{T})}$ & $0.828^{(\mathbf{T})}$ & $0.348^{(\mathbf{T})}$ \\
\hline & No & $54(54 \%)$ & $26(52 \%)$ & $34(68 \%)$ & \multirow{2}{*}{$0.817^{(\mathbf{C})}$} & \multirow{2}{*}{$0.101^{(\mathbf{C})}$} & \multirow{2}{*}{$0.102^{(\mathbf{C})}$} \\
\hline Smoking & g Yes & $46(46 \%)$ & $24(48 \%)$ & $16(32 \%)$ & & & \\
\hline
\end{tabular}

(T) Student t-test of significance. (C) Chi-Square test of significance. *Data are presented as mean \pm SD, median (Range), or number (\%). P value $\leq 0.05, \mathrm{BMI}=$ body mass index. *P- Value (1): Between controls and (AF without TE) group. *P-Value (2): Between controls and (AF with TE) group. *P-Value (3): Between (AF without TE) group and (AF with TE) group.

Regarding comparison between controls and patient's groups, there was a statistically significant difference between patient's groups and controls as regards history of CAD, history of DM and history of hypertension. Patients' groups was more likely to have CAD ( $<<0.001)$, hypertension $(\mathrm{p}<0.001)$ or diabetes $(\mathrm{p}<0.001)$, but there was no statistically significant differences between the two patient's groups as regards history of hypertension $(\mathrm{p}=0.383)$, diabetes $(\mathrm{p}=0.334), \mathrm{CAD}(\mathrm{p}=0.817)$, and $\mathrm{HF}(\mathrm{P}=0.26)$ (Table 2$)$.

Table (2): Comparison between the two patient's groups as regards medical comorbidities

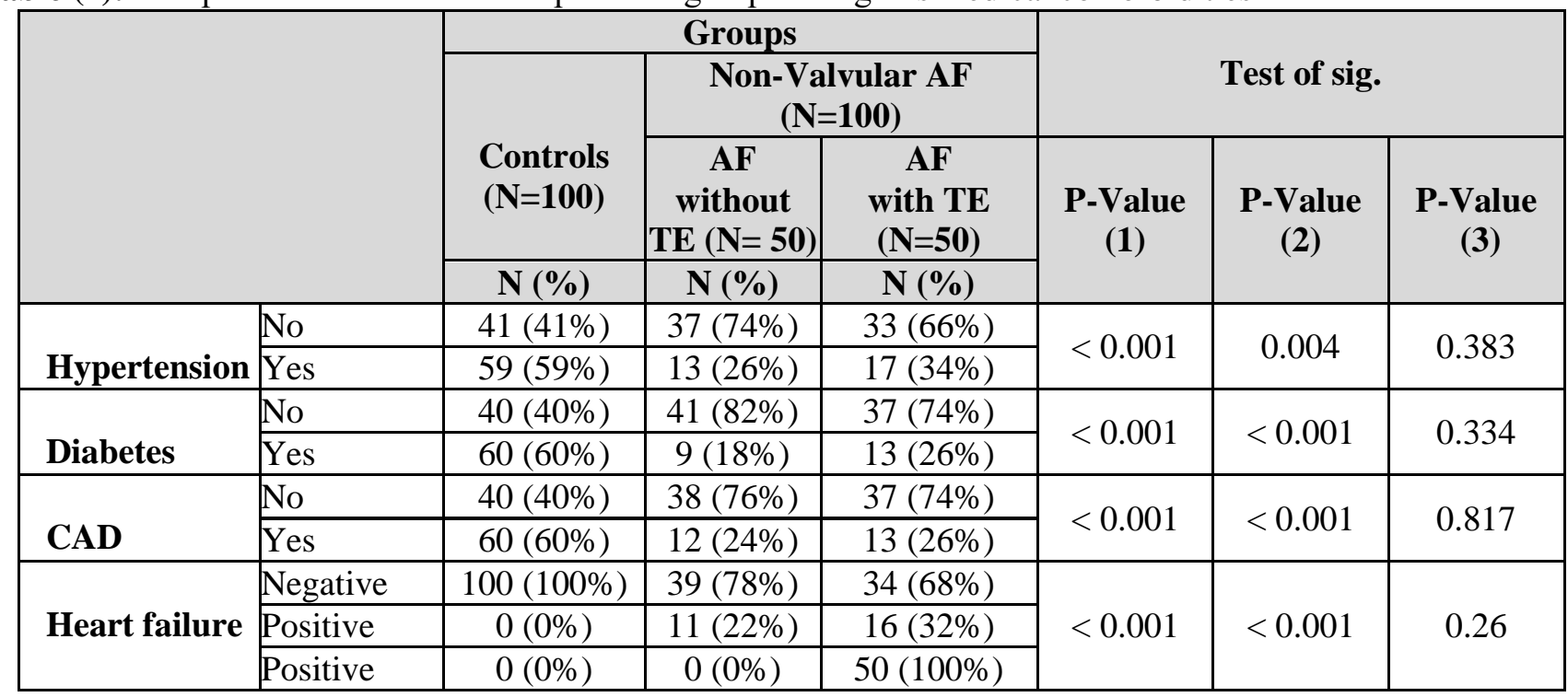

$\mathrm{P}$ value $\leq 0.05, \mathrm{CAD}=$ coronary artery disease. ${ }^{*} \mathrm{P}-$ Value $(1)$ : Between Controls and (AF without TE) group. $* \mathrm{P}-$ Value (2): Between Controls and (AF with TE) group. *P-Value (3): Between (AF without TE) group and (AF with TE) group.

There was statistically significant difference between patient's groups and controls as regards galectin-3 level ( $\mathrm{p}$ $<0.001)$, LVEF ( $\mathrm{p}<0.001)$ and $\mathrm{CHA}_{2} \mathrm{DS}_{2}-\mathrm{VASc}$ scoring $(\mathrm{p}<0.001)$. Patients with AF had significantly higher galectin-3 level than controls. There was statistically significant difference between patient's groups as regards galectin-3 level $(\mathrm{P}=0.001)$. Group $(\mathrm{A})$ had significantly higher galectin-3 level than group $(\mathrm{B})$. Also, there was statistically significant difference between patient's groups as regards $\mathrm{CHA}_{2} \mathrm{DS}_{2}-\mathrm{VASc}$ scoring $(\mathrm{P}<0.001)$, group (A) had significantly higher $\mathrm{CHA}_{2} \mathrm{DS}_{2}$-VASc scoring than group (B) s shown in table (3).

Table (3): Comparison between patient's groups as regards galectin-3 level and $\mathrm{CHA}_{2} \mathrm{DS}_{2}-\mathrm{VASc}$ scoring 


\begin{tabular}{|c|c|c|c|c|c|c|}
\hline & \multirow{3}{*}{$\begin{array}{c}\begin{array}{c}\text { Controls } \\
(\mathrm{N}=100)\end{array} \\
\begin{array}{c}\text { Mean } \pm \mathrm{SD} \\
\text { Median }\end{array}\end{array}$} & \multicolumn{2}{|c|}{ Non-Valvular AF $(\mathrm{N}=100)$} & \multirow{3}{*}{$\begin{array}{c}\text { P-Value } \\
\text { (1) }\end{array}$} & \multirow{3}{*}{$\begin{array}{c}\text { P-Value } \\
\text { (2) }\end{array}$} & \multirow{3}{*}{$\begin{array}{c}\text { P-Value } \\
\text { (3) }\end{array}$} \\
\hline & & $\begin{array}{l}\text { AF without } T E \\
(N=50)\end{array}$ & $\begin{array}{c}\text { AF with TE } \\
(\mathbf{N}=50)\end{array}$ & & & \\
\hline & & $\begin{array}{c}\text { Mean } \pm \text { SD } \\
\text { Median }\end{array}$ & $\begin{array}{c}\text { Mean } \pm \text { SD } \\
\text { Median }\end{array}$ & & & \\
\hline Serum Galectin & $5.8 \pm 1.21$ & $13.87 \pm 3.78$ & $17.14 \pm 4.32$ & $<0.001$ & $<0.001$ & $<0.001$ \\
\hline CHA2DS2-VASc scoring & $0(0-0)$ & $1(0-2)$ & $4(3-4)$ & $<0.001$ & $<0.001$ & $<0.001$ \\
\hline
\end{tabular}

$\mathrm{P}$ value $\leq 0.05,{ }^{*} \mathrm{P}-$ Value (1): Between Controls and (AF without TE) group. *P-Value (2): Between Controls and (AF with TE) group. *P-Value (3): Between (AF without TE) group and (AF with TE) group.

There were statistically significant differences between patient's groups and controls concerning LA/LAA thrombus ( $\mathrm{p}<0.001)$, LA/LAA dense SEC $(\mathrm{p}<0.001)$, and LAA flow velocity $(\mathrm{p}<0.001)$. Also, there were statistically significant differences between patient's groups as regards LAA flow velocity $(\mathrm{p}<0.001)$, LA/LAA dense SEC $(p=0.037)$ and LA/LAA thrombus $(p=0.037)$. Patients of group A had lower LAA flow velocity and higher incidence of LA/LAA thrombus and dense SEC than patients of group B (Table 4).

Table (4): Comparison between patients and control regarding echocardiographic parameters

\begin{tabular}{|c|c|c|c|c|c|c|c|}
\hline & \multicolumn{3}{|c|}{ Groups } & \multirow{2}{*}{\multicolumn{3}{|c|}{ Test of sig. }} \\
\hline & & \multirow{3}{*}{$\begin{array}{c}\begin{array}{c}\text { Controls } \\
(\mathrm{N}=100)\end{array} \\
\mathrm{N}(\%)\end{array}$} & \multicolumn{2}{|c|}{$\begin{array}{c}\text { Non-Valvular AF } \\
(\mathrm{N}=100)\end{array}$} & & & \\
\hline & & & $\begin{array}{l}\text { AF without } \\
\text { TE }(N=50)\end{array}$ & $\begin{array}{c}\text { AF with TE } \\
(\mathbf{N}=50)\end{array}$ & \multirow{2}{*}{$\begin{array}{c}\text { P-Value } \\
\text { (1) }\end{array}$} & \multirow{2}{*}{$\begin{array}{c}\text { P-Value } \\
(2)\end{array}$} & \multirow{2}{*}{$\begin{array}{c}\text { P-Value } \\
\text { (3) }\end{array}$} \\
\hline & & & $\mathbf{N}(\%)$ & $\mathbf{N}(\%)$ & & & \\
\hline \multirow{2}{*}{$\begin{array}{l}\text { LAA flow } \\
\text { velocity M/S }\end{array}$} & $<0.25$ & $0(0 \%)$ & $12(24 \%)$ & $35(70 \%)$ & \multirow[b]{2}{*}{$<0.001$} & \multirow[b]{2}{*}{$<0.001$} & \multirow[b]{2}{*}{$<0.001$} \\
\hline & $>0.25$ & $100(100 \%)$ & $38(76 \%)$ & $15(30 \%)$ & & & \\
\hline \multirow{2}{*}{$\begin{array}{l}\text { LA/LAA } \\
\text { dense SEC }\end{array}$} & Negative & $100(100 \%)$ & $42(84 \%)$ & $25(50 \%)$ & \multirow[b]{2}{*}{$<0.001$} & \multirow[b]{2}{*}{$<0.001$} & \multirow[b]{2}{*}{$<0.001$} \\
\hline & Positive & $0(0 \%)$ & $8(16 \%)$ & $25(50 \%)$ & & & \\
\hline \multirow{2}{*}{$\begin{array}{l}\text { LA/LAA } \\
\text { thrombus }\end{array}$} & Negative & $100(100 \%)$ & $47(94 \%)$ & $40(80 \%)$ & \multirow[b]{2}{*}{0.013} & \multirow[b]{2}{*}{$<0.001$} & \multirow[b]{2}{*}{0.037} \\
\hline & Positive & $0(0 \%)$ & $3(6 \%)$ & $10(20 \%)$ & & & \\
\hline
\end{tabular}

$\mathrm{P}$ value $\leq 0.05, \mathrm{LA}=$ left atrium. $\mathrm{LAA}=$ left atrial appendage. $\mathrm{SEC}=$ spontaneous echo contrast $* \mathrm{P}-$ Value $(1)$ : Between Controls and (AF without TE) group. *P-Value (2): Between Controls and (AF with TE) group. *P-Value (3): Between (AF without TE) group and (AF with TE) group.

There were statistically positive correlations between serum galectin- 3 and LA/LAA dense SEC $(r=0.645, p$ $<0.001)$. Also, there were statistically positive correlations between serum Gelactin-3 and LA/LAA thrombus ( $\mathrm{r}$ $=0.529, \mathrm{p}<0.001)$. In contrary, there were statistically negative correlations between serum galectin-3 and LAA flow velocity $(\mathrm{r}=-0.783, \mathrm{p}<0.001)($ Table 5$)$.

Table (5): Correlation analysis between serum galectin-3 and echocardiographic parameters

\begin{tabular}{|l|l|c|c|c|}
\hline \multicolumn{2}{|c|}{ Non-Valvular AF (N=100) } & $\begin{array}{c}\text { LA/LAA } \\
\text { thrombus }\end{array}$ & $\begin{array}{c}\text { LA/LAA } \\
\text { dense SEC }\end{array}$ & $\begin{array}{c}\text { LAA flow } \\
\text { velocity (ms) }\end{array}$ \\
\hline \multirow{2}{*}{$\begin{array}{l}\text { Serum } \\
\text { Galectin }\end{array}$} & Correlation Coefficient (r) & 0.529 & 0.645 & -0.783 \\
\cline { 2 - 5 } & P-Value & $<0.001$ & $<0.001$ & $<0.001$ \\
\cline { 2 - 5 } & Sig. & $\mathrm{S}$ & $\mathrm{S}$ & $\mathrm{S}$ \\
\hline
\end{tabular}

*Data are presented as odds ratio and $95 \%$ confidence interval. $\mathrm{P}$ value $\leq 0.05, \mathrm{LA} / \mathrm{LAA}=$ left atrium and left atrial appendage, $\mathrm{SEC}=$ spontaneous echo contrast

The ROC curve results of galectin-3 for study groups showed that galectin-3 was a significant discriminator between AF and normal population. At cutoff value of $\geq 7.25 \mathrm{ng} / \mathrm{mL}$. The galectin-3 yielded a sensitivity of $81 \%$ and specificity of $77 \%$ for the detection of AF (Table 6). Also, the galectin-3 was a significant discriminator of the presence of LAA flow velocity of less than $25 \mathrm{~m} / \mathrm{s}$ at cut-off value of $8.25 \mathrm{ng} / \mathrm{mL}$ with a sensitivity of $82 \%$ and specificity of 70\%. In addition, galectin-3 was a significant discriminator of the presence of LA/LAA dense SEC at cut-off value of $8.25 \mathrm{ng} / \mathrm{mL}$ with a sensitivity of $91 \%$ and specificity of $70 \%$. The galectin-3 was a significant discriminator of the presence of LA/LAA thrombus at cut-off value of $13.8 \mathrm{ng} / \mathrm{mL}$ with a sensitivity of $73 \%$ and specificity of $68 \%$ (Table 7).

Table (6): Area under the curve and the diagnostic accuracy of Galectin-3 for study's groups $(n=200)$

\begin{tabular}{l|l|l|l|l|l} 
AUC & 95\% CI & P- & Cut-off & Sensitivity & Specificity \\
\hline
\end{tabular}




\begin{tabular}{|c|c|c|c|c|c|c|}
\hline & & & Value & point & & \\
\hline $\begin{array}{c}\text { AF versus } \\
\text { Control }\end{array}$ & 0.84 & 0.73 to 0.99 & $<0.001$ & $\geq 7.25 \mathrm{ng} / \mathrm{mL}$ & $81 \%$ & $77 \%$ \\
\hline
\end{tabular}

*AUC: area under curve; CI: Confidence interval. P value $\leq 0.05$

Table (7): Area under the curve and the diagnostic accuracy of galectin-3 in nonvalvular AF patients ( $\mathrm{n}=100)$

\begin{tabular}{|l|c|c|c|c|c|c|}
\hline & AUC & $\mathbf{9 5 \%}$ CI & $\begin{array}{c}\text { P- } \\
\text { Value }\end{array}$ & $\begin{array}{c}\text { Cut-off } \\
\text { point }\end{array}$ & Sensitivity & Specificity \\
\hline $\begin{array}{l}\text { LA/LAA } \\
\text { thrombus }\end{array}$ & 0.8 & 0.69 to 0.89 & $<0.001$ & $\geq 13.8$ & $73 \%$ & $68 \%$ \\
\hline LA/LAA dense SEC & 0.94 & 0.87 to 0.99 & $<0.001$ & $\geq 8.25$ & $91 \%$ & $70 \%$ \\
\hline $\begin{array}{l}\text { LAA flow } \\
\text { velocity MS }\end{array}$ & 0.84 & 0.73 to 0.99 & $<0.001$ & $\geq 8.25$ & $82 \%$ & $70 \%$ \\
\hline
\end{tabular}

AUC: area under curve; CI: Confidence interval. P value $\leq 0.05$

\section{DISCUSSION}

Atrial fibrillation is considered one of the most common cardiac arrhythmias as it affects nearly 30 million people worldwide ${ }^{(\mathbf{1 2})}$. This arrhythmia remains one of the major causes of stroke, heart failure, sudden death, and cardiovascular morbidity in the world. It is believed that this disease occurs as a result of fibrosis, which may affect left atrium ${ }^{(\mathbf{1})}$. Galectin- 3 is an $\alpha$-galactoside-binding lectin that has been shown to mediate cell-to- cell and cell-toextracellular matrix interactions and act as a novel chemo-attractant for monocytes and macrophages ${ }^{(6)}$. It has an important role in a number of fibrotic conditions, including cardiac fibrosis ${ }^{(13)}$. Also, it has important roles in the cardiovascular inflammation and fibrosis that result in cardiac remodeling. Higher circulating galectin-3 concentrations were found to be related with increased risk of $\mathrm{AF}{ }^{(14)}$. However, it is not clear whether galectin-3 is a possible predictor for thrombus formation in patients with AF. Hence, we conducted the current study to investigate whether serum galectin-3 levels can be used as a predictor of thromboembolism in non-valvular AF patients.

There were high serum galectin-3 level in AF group compared to control group with higher level in subgroup Ib compared to subgroup Ia, positive correlation between galectin-3 and CHADS-VASc scoring system in nonvalvular AF patient's and positive correlations between serum galectin-3 and LA/LAA dense SEC. Also, there was positive correlation between serum galectin-3 and LA/LAA thrombus in nonvalvular AF patients. In contrary, there was negative correlation between serum galectin-3 and LAA flow velocity in nonvalvular AF patient's.

Our study showed that a significant association between high serum galectin-3 and incidence of AF. In AF group, galectin-3 level was 5.8 \pm 1.21 while in control group, it was $15.51 \pm 4.36$ ( $\mathrm{P}$ value $<0.001)$. Also, serum galectin-3 has a sensitivity of $81 \%$ and specificity of $77 \%$ to detect $\mathrm{AF}$ incidence $[\mathrm{AUC}=0.84,95 \% \mathrm{CI}=(0.73-0.99)]$. Our results are consistent with several studies where Szadkowska et al. ${ }^{(15)}$ conducted a study on 145 patients with first acute MI and underwent with primary percutaneous coronary intervention (PCI) with stent implantation.

They found that elevated serum galectin-3 level was associated with a higher rate of new-onset AF. Sonmez et al. ${ }^{\left({ }^{16)}\right.}$ studied 52 non-valvular AF and 33 patients with sinus rhythm to detect markers that might predict $\mathrm{AF}$ and affect atrial remodeling. Galectin-3 was among markers that was higher in patients with AF (1204 versus $1166 \mathrm{pg} / \mathrm{ml}, \mathrm{p}=0.001$ ) and had a strong positive correlation with left atrium index volume (LAVI) $(r=640, p=0.021)$. Our findings are also in agreement with another casecontrol study on 76 patients with AF who were above age of 75 years old. They showed the role of galectin3 in the pathogenesis of AF. Results showed that serum galectin-3 $(\mathrm{OR}=87.53,95 \% \mathrm{Cl}\{6.1$ to $1,265.03\}, \quad \mathrm{P}$ value $=0.001)$ was independent predictor of $\mathrm{AF}$. In correlation analysis, serum galectin-3 was only correlated with left atrium index volume ${ }^{(\mathbf{1 6})}$. Our findings are also in agreement with a recent meta-analysis on seven prospective cohort studies including 645 AF patients. They investigated the relationship between baseline serum galectin-3 levels and $\mathrm{AF}$ recurrence in patients undergoing catheter ablation. They concluded that high baseline serum galectin-3 levels may be associated with increased risk of $\mathrm{AF}$ recurrence after catheter ablation (17). Similar to our findings also a systematic review and meta-analysis on 28 studies involving 10830 patients examined the association of galecti- 3 and incidence of AF. They concluded that galectin-3 was a higher in patients with persistent AF than those with 
paroxysmal AF. Moreover it can predict AF incidence and recurrence after treatment ${ }^{(\mathbf{1 8})}$.

On the other hand, two previous studies reported that galectin-3 level was not associated with AF incidence. Zakeri et al. ${ }^{(19)}$ study included 216 patients with heart failure and preserved ejection fraction. In AF group galectin-3 level was 14.3 (11.719.7) $\mathrm{ng} / \mathrm{ml}$ while in sinus rhyme group, it was 13.6 $(10.8-16.9) \mathrm{ng} / \mathrm{mL}$ with no significant difference between both groups $(p=0.15)$. These findings may be due to small number of patients who had AF (only $37 \%$ ), which is not enough to observe significant difference in galectin-3 level between groups.

In our study, serum galectin-3 had a strong positive correlation with CHADS-VASc scoring system $(r=0.75, p$ value $<0.001)$ and the total score was higher in AF patients with thromboembolic event than AF patients without thromboembolic event (range was 3 to 4 versus 0 to $2, p$ value $<0.001$, respectively). Our findings are in agreement with previous studies where Tang $\boldsymbol{e t} \boldsymbol{a l} .{ }^{(\mathbf{2 0})}$ study reported that galectin-3 was identified as an independent determinant for CHADS-VASc score (OR 0.091, $95 \% \mathrm{CI}=\{0.008-0.981\}, \mathrm{p}=0.048)$. In another study higher serum galectin-3 levels were associated with higher both CHADS2 ( $\mathrm{p}=0.008)$ and CHA2DS2$\operatorname{VASC}(\mathrm{p}=0.016)$ score $^{(21)}$.

In our study, serum galectin-3 had a positive correlation with LA/LAA dense SEC ( $r=0.645, p$ $<0.001)$ and the presence of left atrial/left atrial appendage-located spontaneous echo contrast was higher in AF patients with thromboembolic events than AF patients without thromboembolic events. Our findings are in agreement with previous studies where Kocyigit et al. (22) study found that patients with higher galectin-3 levels $(\mathrm{P}<.001)$ more frequently had dense SEC in LA/LAA $(\mathrm{P}<.001)$, while Tang $\boldsymbol{e t} \boldsymbol{a l}$. (20) study found that there were non-statistically significant results $(\mathrm{p}=0.116)$. Also, there were positive correlations between serum galectin-3 and LA/LAA thrombus $(\mathrm{r}=0.529, \mathrm{p}<0.001)$.

Similar to our findings, Tang et al. ${ }^{(20)}$ study showed that high level of galectin-3 levels was associated with occurrence of LAA thrombus ( $p<$ 0.01 ). There were strong negative correlations between serum galectin-3 levels and LAA flow velocity $(\mathrm{r}=-0.783, \mathrm{p}<0.001)$. Our findings are in agreement with previous study, in Kocyigit et al. ${ }^{(22)}$. They found a negative correlation between LAA flow velocity and serum galectin-3 levels $(\mathrm{r}=-.440$, $\mathrm{P}<.001)$. On other hand, Tang et al. ${ }^{(20)}$ reported that the correlation wasn't statistically significant $(\mathrm{p}=$ $0.022)$.
Our result showed that serum galectin-3 was a significant predictor for thromboembolic event $[\mathrm{OR}=2.4,95 \% \mathrm{CI}=\{1.3: 4.3\}, \mathrm{P}$ value $=0.005]$ and with cut of value $8.25 \mathrm{ng} / \mathrm{mL}$, sensitivity of $73 \%$ and specificity of $68 \%$ for the thrombus detection [AUC $=$ $0.80,95 \% \mathrm{CI}=\{0.69-0.89\}]$. Similarly, a study on 153 patients with non-valvular AF showed that high levels of galectin-3 were also a predicator for LAA thrombus formation $(\mathrm{OR}=-12.925,95 \% \mathrm{CI}=\{-16.2:-9.6\}, \mathrm{P}$ value $<0.01$ ) and it had a sensitivity of $90.9 \%$ and $96.9 \%$ specificity for the thrombus detection. But they set a cut off higher than the one we determined in our study $(>18.95 \mathrm{ng} / \mathrm{ml}){ }^{(\mathbf{2 0})}$. Regarding the presence of left atrial/left atrial appendage-located spontaneous echo contrast, our result showed that galectin-3 had a sensitivity of $91 \%$ and $70 \%$ specificity [AUC $=0.94$, $95 \% \mathrm{CI}=\{0.87-0.99\}]$. Our findings are in agreement with previous studies of Kocyigit $\boldsymbol{e t}$ al. ${ }^{(22)}$ who conducted a study on 65 persistent AF patients and showed that high levels of galectin-3 were also a predicator for the presence of left atrial/left atrial appendage-located spontaneous echo contrast (AUC: $0.909,95 \%$ CI: $0.840-0.977, \mathrm{P}<.001)$ and galectin-3 had a sensitivity of $91 \%$ and $79 \%$ specificity (AUC= $0.90,95 \% \mathrm{CI}=\{0.84-0.97\})$. Additionally, regarding left atrial appendage flow velocity, our result showed that galectin-3 had a sensitivity of $82 \%$ and $70 \%$ specificity $(\mathrm{AUC}=0.84,95 \% \mathrm{CI}=\{0.73-0.99\})$. In line with these findings, Kocyigit et al. ${ }^{\text {(22) }}$ reported similar results that high levels of galectin-3 predicted LAAFV $<0.25 \mathrm{~m} / \mathrm{s}$ with a sensitivity and specificity of $86 \%$ and $76 \%$ respectively (AUC:0.851,95\%CI: $0.732-$ $0.971, \mathrm{P}<.001)$.

\section{CONCLUSION}

Galectin-3 level is a possible predictor for thromboembolism in patients with non-valvular AF. Nevertheless, further studies are still needed to confirm our findings.

\section{REFERENCES}

1. Ball J, Carrington M, McMurray J et al. (2013): Atrial fibrillation: Profile and burden of an evolving epidemic in the 21st century. Int J Cardiol., 167 (5): 1807-24.

2. Xiong Q, Proietti M, Senoo $K$ et al. (2015): Asymptomatic versus symptomatic atrial fibrillation: A systematic review of age/gender differences and cardiovascular outcomes. In International Journal of Cardiology, 191: 172- 177.

3. Ederhy S, Di Angelantonio E, Dufaitre G et al. (2012): C-reactive protein and transesophageal echocardiographic markers of thromboembolism in patients with atrial fibrillation. International Journal of Cardiology, 159 (1): 40-46.

4. Cattaneo V, Tribulatti M, Carabelli J et al. (2014): Galectin-8 elicits pro-inflammatory activities in the endothelium. Glycobiology, 24 (10): 966-973.

5. Ji F, Zhang S, Jiang et al. (2017): Diagnostic and prognostic value of galectin-3, serum creatinine, and 
cystatin $\mathrm{C}$ in chronic kidney diseases. Journal of Clinical Laboratory Analysis, 31 (5): 22074-82.

6. Maiolino G, Rossitto G, Pedon L et al. (2015): Galectin-3 Predicts Long-Term Cardiovascular Death in High-Risk Patients with Coronary Artery Disease. Arteriosclerosis, Thrombosis, and Vascular Biology, 35 (3): 725-732.

7. Gurses K, Yalcin M, Kocyigit D et al. (2015): Effects of persistent atrial fibrillation on serum galectin-3 levels. American Journal of Cardiology, 115(5): 647-651.

8. Yalcin M, Gurses K, Kocyigit D et al. (2015): The Association of Serum Galectin-3 Levels with Atrial Electrical and Structural Remodeling. Journal of Cardiovascular Electrophysiology, 26 (6): 635-640.

9. Christenson R, Duh S, Wu A et al. (2010): Multi-center determination of galectin-3 assay performance characteristics. Clinical Biochemistry, 43 (7-8): 683690 .

10.Douglas $\mathrm{P}$, Haines $\mathrm{D}$, Lai $\mathrm{W}$ et al. (2011): ACCF/ASE/AHA/ASNC/HFSA/

HRS/SCAI/SCCM/SCCT/SCMR 2011, Appropriate use criteria for echocardiography. Journal of the American Society of Echocardiography, 24 (3): 229-267.

11.Lang $R$, Bierig $M$, Devereux $R$ et al. (2005): Recommendations for chamber quantification. Journal of the American Society of Echocardiography, 18 (12): 1440-1463.

12.Jauch E, Saver J, Chair V et al. (2013): Guidelines for the early management of patients with acute ischemic stroke: a guideline for healthcare professionals from the American Heart Association/American Stroke Association. Stroke, 44 (3): 870-947.

13.Sharma U, Pokharel S, van Brakel T et al. (2004): Galectin-3 marks activated macrophages in failure-prone hypertrophied hearts and contributes to cardiac dysfunction. Circulation, 110 (19): 3121-3128.
14.Ho J, Yin X, Levy D et al. (2014): Galectin 3 and incident atrial fibrillation in the community. American Heart Journal, 167 (5): 729-734.

15. Szadkowska I, Wlazel RN, Migała M et al. (2013): The association between galectin-3 and clinical parameters in patients with first acute myocardial infarction treated with primary percutaneous coronary angioplasty. Cardiology Journal, 20 (6): 577-582.

16.Sonmez O, Ertem F, Vatankulu $M$ et al. (2014): Novel fibro-inflammation markers in assessing left atrial remodeling in non-valvular atrial fibrillation. Med Sci Monit., 20: 463-470.

17.Zhang $G$ and Wu Y (2019): Circulating galectin-3 and atrial fibrillation recurrence after catheter ablation: A meta-analysis. Cardiovascular Therapeutics, https://doi.org/10.1155/2019/4148129

18. Gong M, Cheung A, Wang Q et al. (2020): Galectin-3 and risk of atrial fibrillation: A systematic review and meta-analysis. Journal of Clinical Laboratory Analysis. J Clin Lab Anal., 34 (3): e23104.

19.Zakeri R, Borlaug B, McNulty $S$ et al. (2014): Impact of Atrial Fibrillation on Exercise Capacity in Heart Failure with Preserved Ejection Fraction. Circulation: Heart Failure, 7 (1): 123-130.

20.Tang $Z$, Zeng $L$, Lin $Y$ et al. (2019): Circulating Galectin-3 is associated with left atrial appendage remodelling and thrombus formation in patients with atrial fibrillation. Heart Lung and Circulation, 28 (6): 923-931.

21. Kornej J, Schmiedl J, Ueberham L et al. (2015): Galectin-3 in Patients with Atrial Fibrillation Undergoing Radiofrequency Catheter Ablation. PLoS One, 10 (4): 15.

22. Kocyigit D, Gurses K, Yalcin M et al. (2017): Serum galectin-3 level as a marker of thrombogenicity in atrial fibrillation. Journal of Clinical Laboratory Analysis, 31 (6): 22120-26. 